\title{
Adaptation of Image Processing technique in identification of earthquake induced anomalous feature from TEC: A new Approach
}

\author{
S Patgiri*, M.Devi, A.K Barbara \\ Department of Physics, Gauhati University \\ Guwahati-781014,Assam \\ *Email-patgirisamiran@gmail.com
}

\begin{abstract}
The basic aim of the paper is to adopt image processing approach for extraction of pre-seismic features from global Total Electron Content (TEC) data with an aim of identification of impending earthquake (EQ).For this purpose an algorithm is developed using 'Color Histogram based Search and Retrieve Technology' in matlab environment where pixel information of the global TEC images are extracted.The conversion of these pixel information into coded form and translation of these cipher symbol into TEC magnitude are discussed in details in the paper.The final result is the comparison of anomalous symbolic pattern with reference toEQ time Equatorial Anomaly and thosereceived in regular environment to identify an impending EQ.The technique is tested in two events and the reliability is assessed through real observation.
\end{abstract}

Key words:TEC, Earthquake, Image Processing,Color Histogram based Search and Retrieve Technology, Equatorial Anomaly

\section{Introduction}

Image processing technique is relatively well known approach for extraction of information from different shades of images [Jenson 2003; Gonzalezetal., 2007;Chitradevi and Srimathi2014]. With the increasing demand of transmission of volume of information and data retrieval, the Image Processing Technique (IPT) merits significantimportance with the application in fields like Atmospheric Remote Sensing, Medical Imaging, Forensic Studies, Material Science, Military,pattern recognition.The different approaches adopted in image processing modes of data retrieval aims at achieving enhancementand segmentationof images along with feature extractionandtheir classification[Jain 1989; Gonzalez etal., 2007; Choras 2007].the retrieval of information from satellite image during natural calamities are proved to be very effective in providing percussive warning, however, this tool is yet to be utilised in extraction of relevant features from parameters like Total Electron Content (TEC), temperature, pressure and relevant atmospheric variabilities.In this aspect we may refer to the work of Devi et al.,2012 where they have 
adopted DTW technique utilised as pattern recognition of TEC features for identifying an impending EQ. Reports of such percussive studies are now available from workers around the globe [Zaslavski et al., 1998; Devi et al., 2001, 2004; Liu et al., 2001, 2002] where EM technique is very fruitfully utilised in identification of an impending EQ by examining anomalous features TEC, critical frequency of F-layer and related parameter. In this aspect it is therefore felt that Image Processing can be utilised as a potential tool and this is the attempt of the paper.

\section{Analysis and Approach}

The main data source for this work is global TEC (https://www.sws.bom.gov.au/Satellite), TEC data collected fromGPS receiver installed at Guwahati $\left(26^{\circ} 10^{\prime} \mathrm{N}, 91^{\circ} 45^{\prime} \mathrm{E}\right)$ are used as supporting inputs when necessary. The main feature of the study will be Equatorial Anomaly, an effect that causes diurnal peak density not at the equator but around $\pm 15^{0}$ geomagnetic latitude throughExB force where $\mathrm{E}$ is the electric field generated by plasma drift and B is the Earth's magnetic field vector at the equator. The position of Guwahati (geomagnetic latitude $15.2^{\circ} \mathrm{N}$, dip angle $37^{\circ} \mathrm{N}$, magnetic latitude $20.64^{\circ} \mathrm{N}$ )being at the anomaly crest zone, the diurnal TEC profile carries signature of this phenomenon. A representativeof this feature present in TEC over Guwahati is shown in figure 1(a) where densityreaches maxima at post noon hours instead of showing its peak at noon. This peak is the result of Appleton Anomaly effect [Walker and Chen 1989; Horvath and Essex 2003;Anderson et al.,2006; Andreeva et al.,2000]. Figure 1(b) is presents a normal condition where density maxima occur at local noon hours.
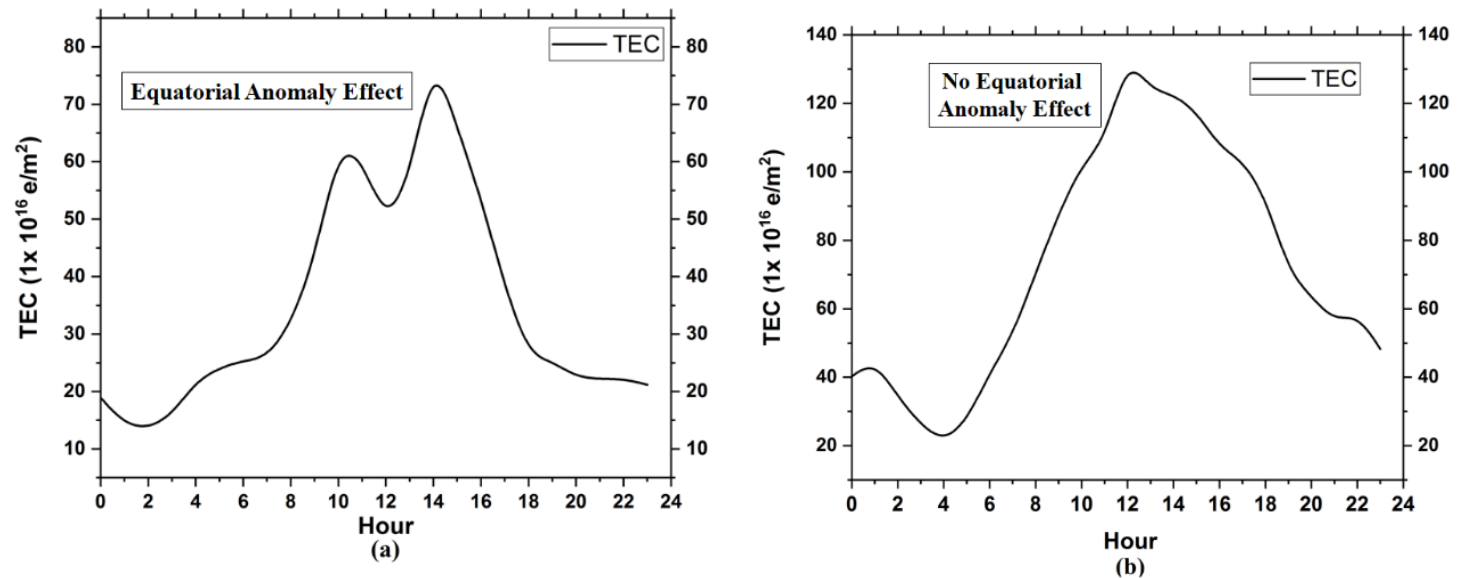

Figure1: Representative Diurnal profile of TEC over Guwahatidisplaying (a) Anomaly effect, (b) Normal feature. 
Such effect is also clearly observed in global TEC contour plot presented in figure 2 where a high density zonesare observed at around $15^{0}-20^{0}$ geographic latitude (covering off-equatorial station both in northern and southern latitudes), $70^{\circ}-110^{\circ}$ Elongitude at 9 UT or around noon local time. This phenomenon is identified as normal equatorial anomaly. The paper examinespossible development of EQ time equatorial anomaly for the case considered here.For this purpose the image processing technique is adopted in Matlab environment as discussed in the next section.

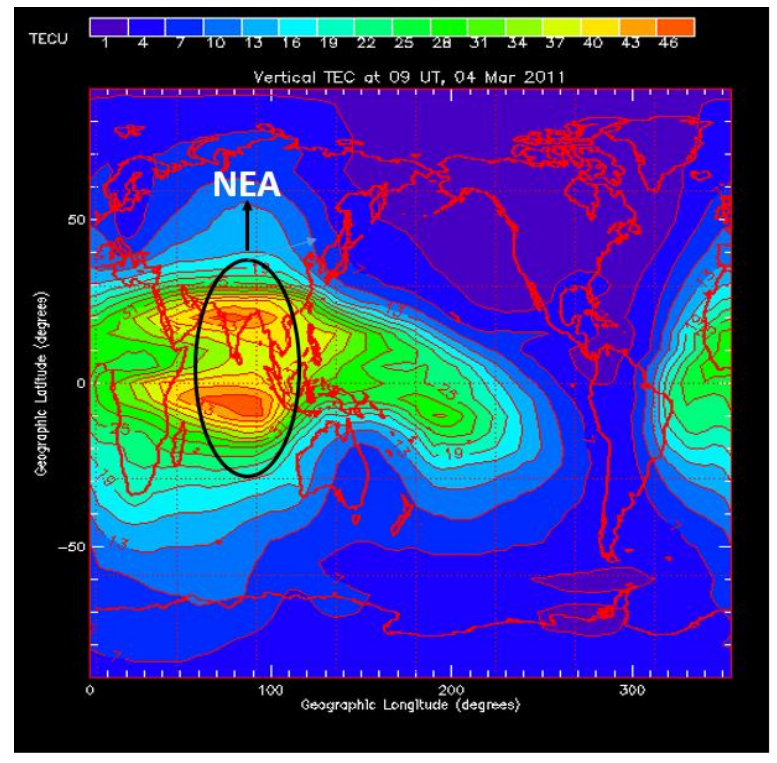

Figure 2: Global TEC map showing Development of Normal Equatorial Anomaly (NEA) arround $80^{\circ} \mathrm{E}$ longitude at 9 UT (noon hours).

\subsection{Technique adopted}

Global TEC data are available as a color image as shown in figure 2. The color intensity of the image varies with magnitude of the TEC. Thus the pixel intensity of such images is directly proportional to the inospheric density profile and hence through pixel intensity character TEC profile can be reconstructed which is the basic aim of this work. For this purpose image feature extraction technique is used where the pixel information of the global TEC images are converted in the form of histogram[Choras 2007; Gonzalez et al., 2009;Shih and Frank 2010;Saber and Tekalp1998; Khotanzad and Hong1990].Color histogram describes the distribution of colours within a defined region of image. The RGB (red, green, 
blue), one of the commonly used color model, is specified in terms of 3-D coordinate system and a subspace within it where each color is represented by a single pointin 3 channel mode (as shown in Figure 4). Statistically, color histogram denotes the joint probability of the intensities of these three colorchannels.Let $\{\mathrm{F}(\mathrm{x}, \mathrm{y}) ; \mathrm{x}=1,2, \ldots, \mathrm{X} ; \mathrm{y}=1,2, \ldots, \mathrm{Y}\}$ be a two-dimensional image pixel array. For colorimages $F(x, y)$ denotes the color value at pixel $(x, y)$ i.e., $F(x, y)=\left\{F_{R}(x, y), F_{G}(x, y), F_{B}(x\right.$, $\mathrm{y})$ \}.For black and white images, $\mathrm{F}(\mathrm{x}, \mathrm{y})$ denotes the grayscale intensity value of pixel $(\mathrm{x}, \mathrm{y})$. Thus for a three-channel image, we will have three such histograms.

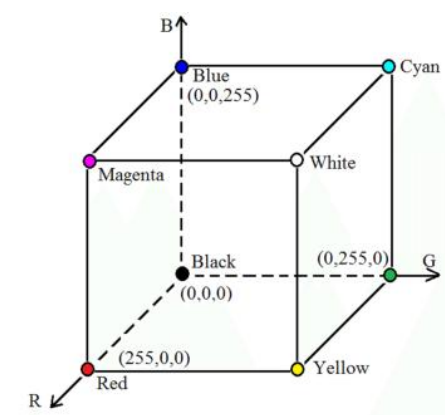

Figure 4: RGB color space.

The analysis started with selection of study zone within $70^{\circ}-130^{\circ}$ Elongitude and $\pm 20^{0} \mathrm{~N}$ latitude considering high seismic activityembedded in this area. For this purpose two EQ events with M>6 are considered. This area of study is then segmented from the entire global TEC map (as shown in the figure 5.a) by using image threshold method. For the two EQ events considered here, 5 quiet days around the EQ date are identified first and RGBpixelinformation of the quiet days over the segmented zone is extracted in histogram form (as shown in Figure 5.b) and created a reference vector $\left(\mathrm{I}_{\mathrm{REF}}\right)$. One can note that during the quiet day (Figure 5.a) at 12UT coveringpost sunset to night hours there is no development of equatorial anomaly at the study area and the pixel patterns from histogram indicate presence of mainly Green and Blue component with minimum Red intensity. This situation we consider as No/Normal Equatorial Anomaly (NEA) depending on the temporal status of the study zone. Next RGB pixel informationof TEC around \pm 7 days for the two EQ events considered here are extracted by histogram method whichformsthe input matrix ( $\mathrm{I}_{\mathrm{INPUT}}$ ) for the selected case.The resultant RGB information $\left(\mathrm{I}_{\mathrm{R}}\right)$ for every hour of a day is then calculated by comparing $\mathrm{I}_{\mathrm{REF}} \mathrm{values}$ with the $\mathrm{I}_{\mathrm{INPUT}}$ matrix, i.e.

$$
\mathrm{I}_{\mathrm{R}}=\mathrm{I}_{\mathrm{INPUT}}-\mathrm{I}_{\mathrm{REF}}
$$


Once the $I_{R}$ value is obtained, its pixel information is translated into six code messages whereeach code has its own identity. With $I_{R}=0$, the corresponding TEC comes to around 40 TECU which is marked as code 3 , i.e., condition of NEA. The code messages 4 and 5 indicatedevelopment of anomalous growth of TEC in relation to NEA. The most significant code here is message 6 that indicates highest TEC values that may increase by two folds from NEA valuesand this is associated with full development of an EQ time Equatorial Anomaly (EEA). Based on these code messages the identification of an impending EQ for the defined cases is presented.

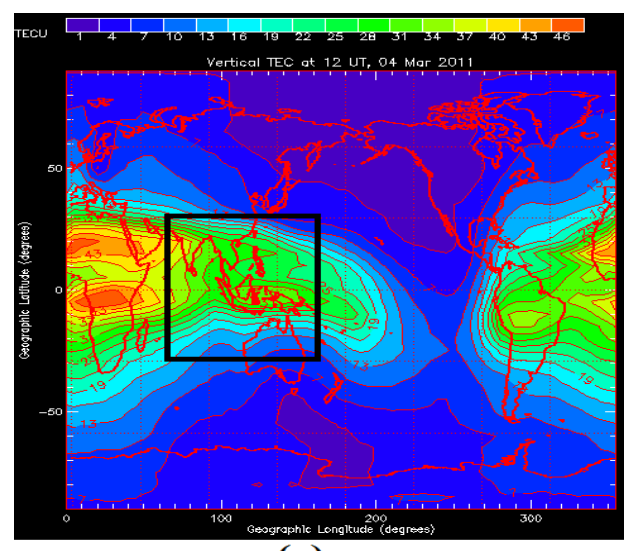

(a)
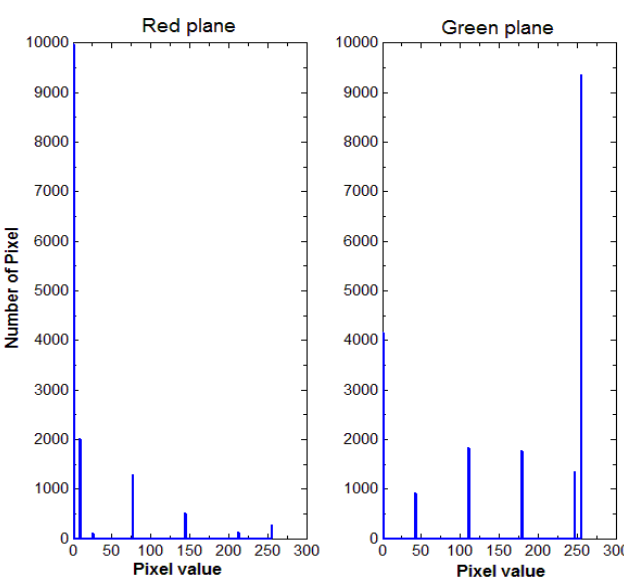

(b)

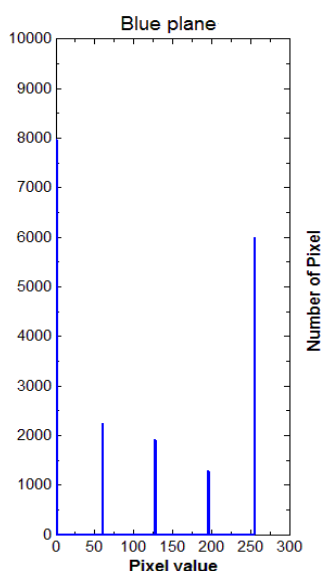

Figure 5: TEC global map for $4^{\text {th }}$ March2011 an example of NO- EQ day. (a) Study zone is shown by a square box in the global TEC image, (b) Pixel distributions of the study zone for Red, Green and Blue plane are shown in terms of histogram.

\section{Results}

\subsection{Case 1: Indonesia Earthquake (IEQ) of $11^{\text {th }}$ April 2012}

Thefirst case considered here is Indonesia earthquake (IEQ) of $M=6.9$ that occurred on $12^{\text {th }}$ April 2012, at $92.42^{0} \mathrm{E}, 0.76^{0} \mathrm{~N}$, a low latitude location. For this purpose, $\mathrm{I}_{\mathrm{REF}}$ is evaluated through extraction of pixel information from global no EQ time TEC contour plot covering $70^{\circ}-160^{\circ} \mathrm{E}$ longitudinal and $\pm 30^{\circ} \mathrm{N}$ latitudinal zone(the area as marked in Figure 5). The $\mathrm{I}_{\text {INPUT }}$ matrix is next evaluated for each day from 5th April to $15^{\text {th }}$ April through pixel information of TEC contour map and the results for a few representative days are displayed in Figure 6. 

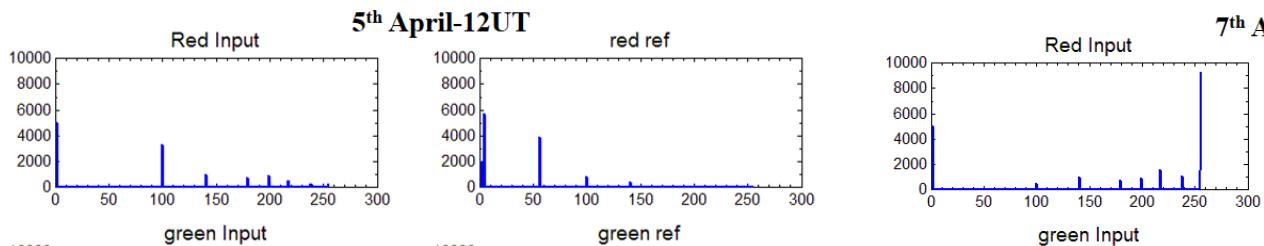

April-12UT
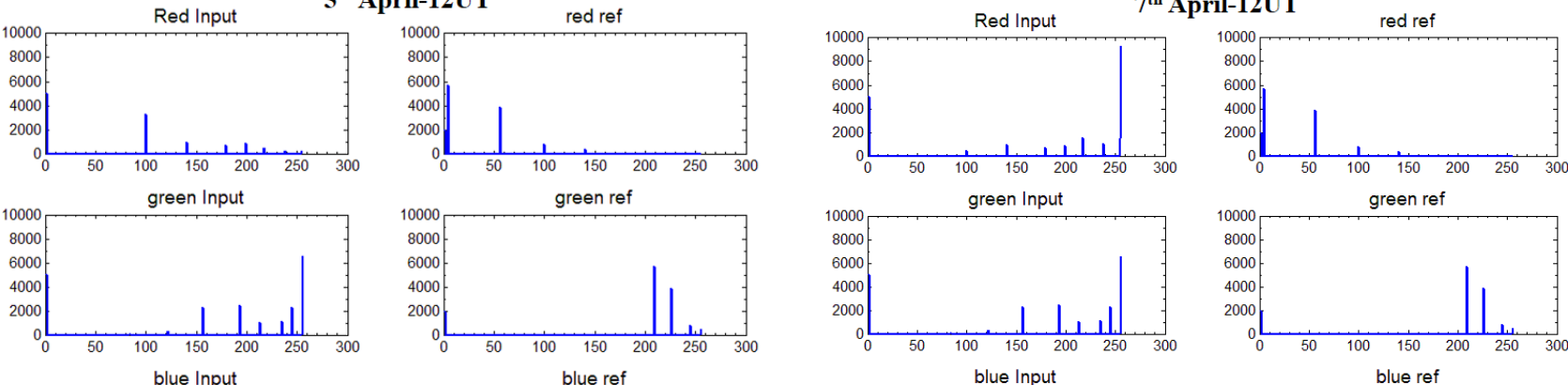

green ref
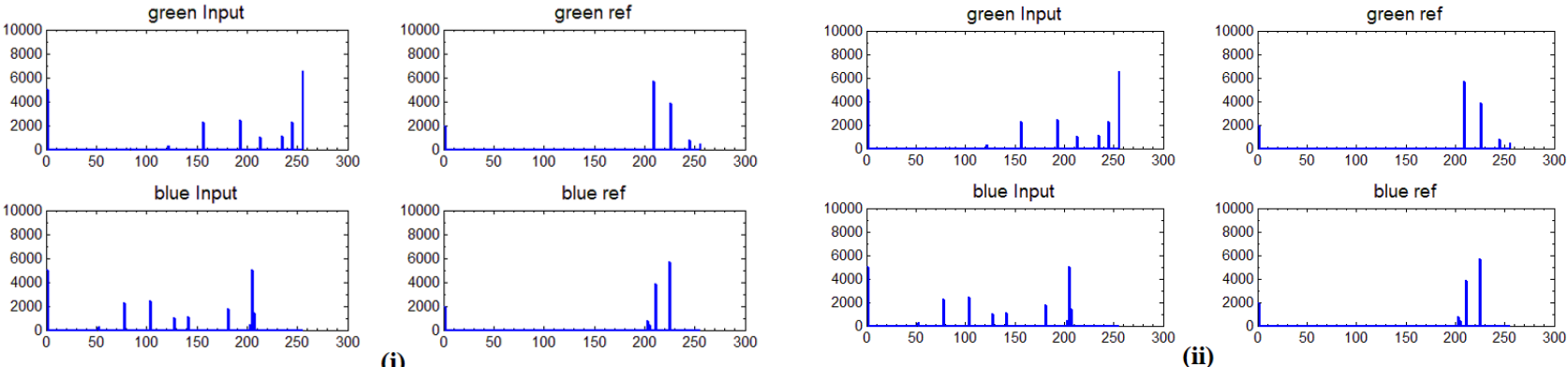

(i)
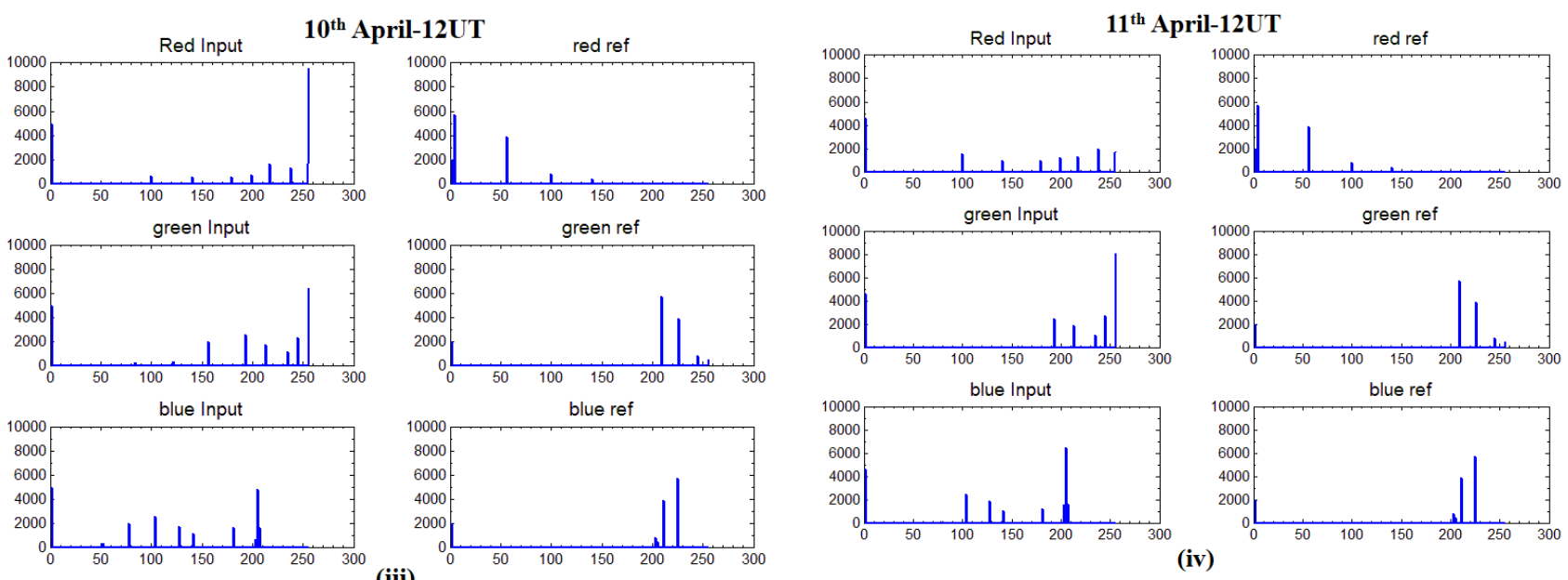

pril-12UT ref
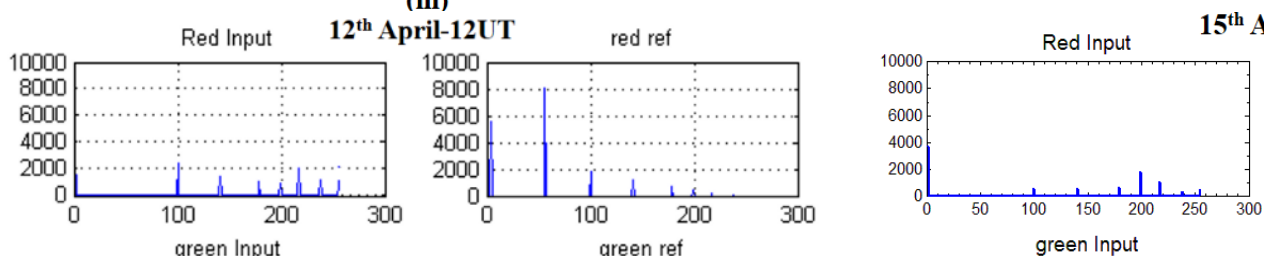

(iv)
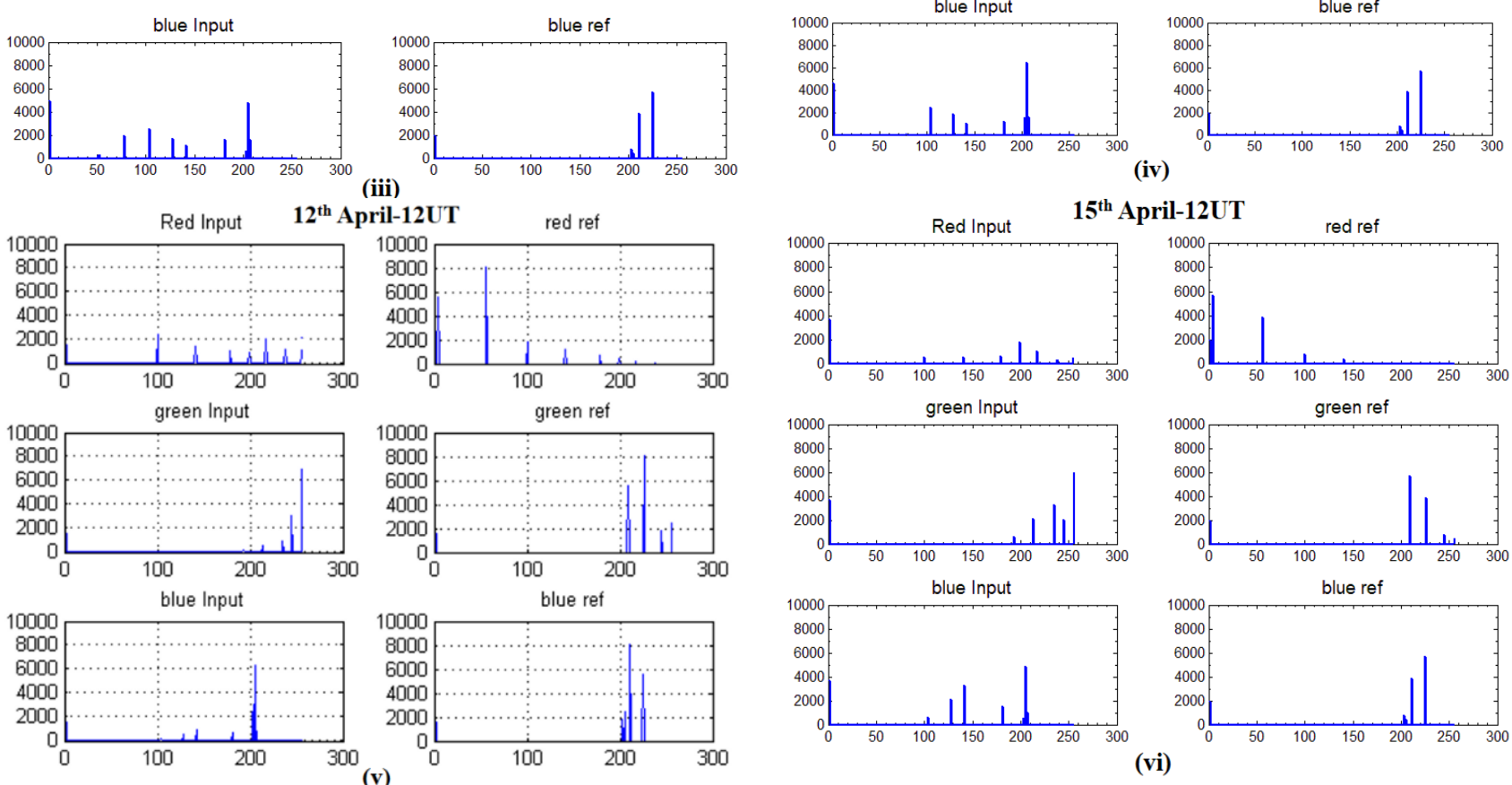

(vi)

Figure 6: The pixel content based histogram analysis of global TEC images shows (i) low intensity of red plane representing NEA status 6 days prior to IEQ. Panel (ii) and (iii) display high pixel intensity of red plane at 12 UT, at the night sector in $90^{\circ} \mathrm{E}-110^{\circ} \mathrm{E}$ on 7 and 10 April indicating high accumulation of density. Panel (iv), (v) and (vi) shows gradual decrease in the pixel intensity of red plane and recover to normal day condition from the EQ day. 
Figure 6(i) shows very low pixel content in the red plane with high intensity in green and blue components on April $5^{\text {th }}$ at 12 UT (night hours) indicating no development of equatorial anomaly ,i.e., NEA status prevails. But on $7^{\text {th }}$ April the pixel distribution of red plane at 256 range bin number shows significantenhancement indicatingdevelopment of an EEA (code 6). The presence of EEA continued up to $10^{\text {th }}$ April that offers aprelude of an impending EQ within $90^{\circ}-110^{\circ} \mathrm{E}$ longitude and $-15^{0}$ to $-20^{0}$ latitude. The red pixel content started decreasing from 11 April. Considering our earlier definition of pointing the EQ day [Devi et al.,2013], we marked $11^{\text {th }}$ April to be the probable day of occurrence of EQ event which is the correct prediction as IEQ did develop on this day.The EEA almost disappeared on $15^{\text {th }}$ April with code message 3.The predicted and actual day of occurrence of the EQ indicate that IPT can be used as a tool for identifying anomalous situation in ionospheric electron content. However the approach still needs further refinement for identifying the epicentre position.

\subsection{Case 2: Japan EQ of 9 and 11 March 2011}

The major Japan EQs (JEQ), ( $\mathrm{M}=7.3 \& \mathrm{M}=9.1$ ) occurred at $135^{\circ}-145^{\circ} \mathrm{E}$ and $35^{\circ}-40^{\circ} \mathrm{N}$ respectively on March 9 and 11, 2011 and as in IEQ in this case too, the pixel information of TEC contour at 12 UT (night time) are extracted in the form of histogram (Figure 7).
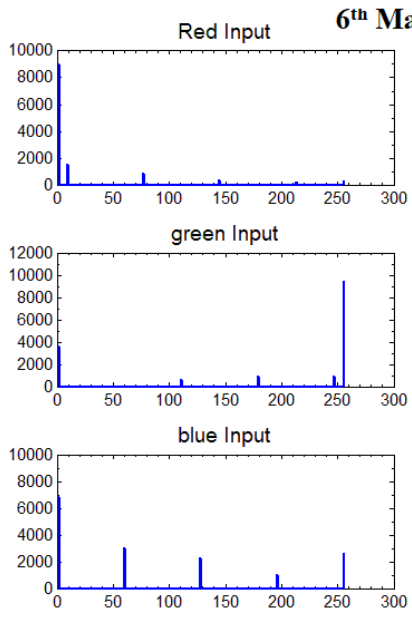

(i)
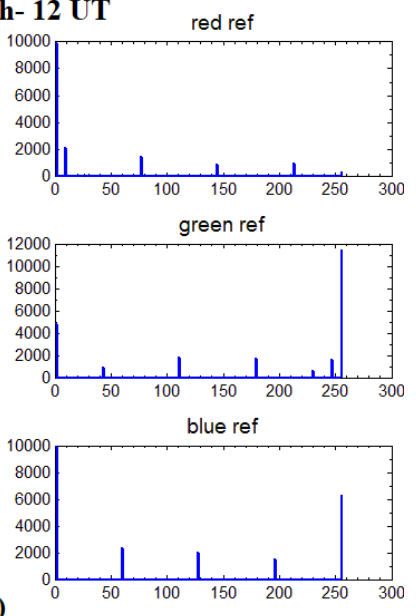

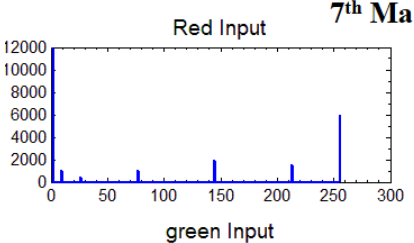

green Input

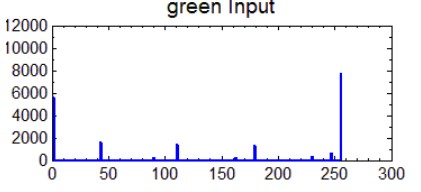

blue Input

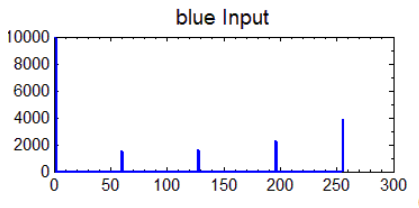

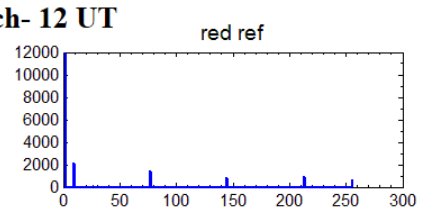

green ref

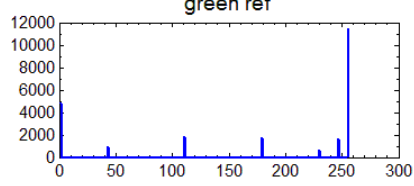

blue ref

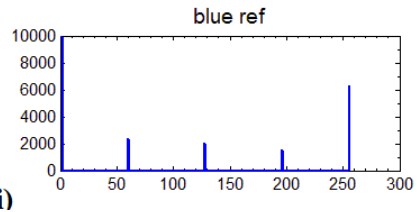



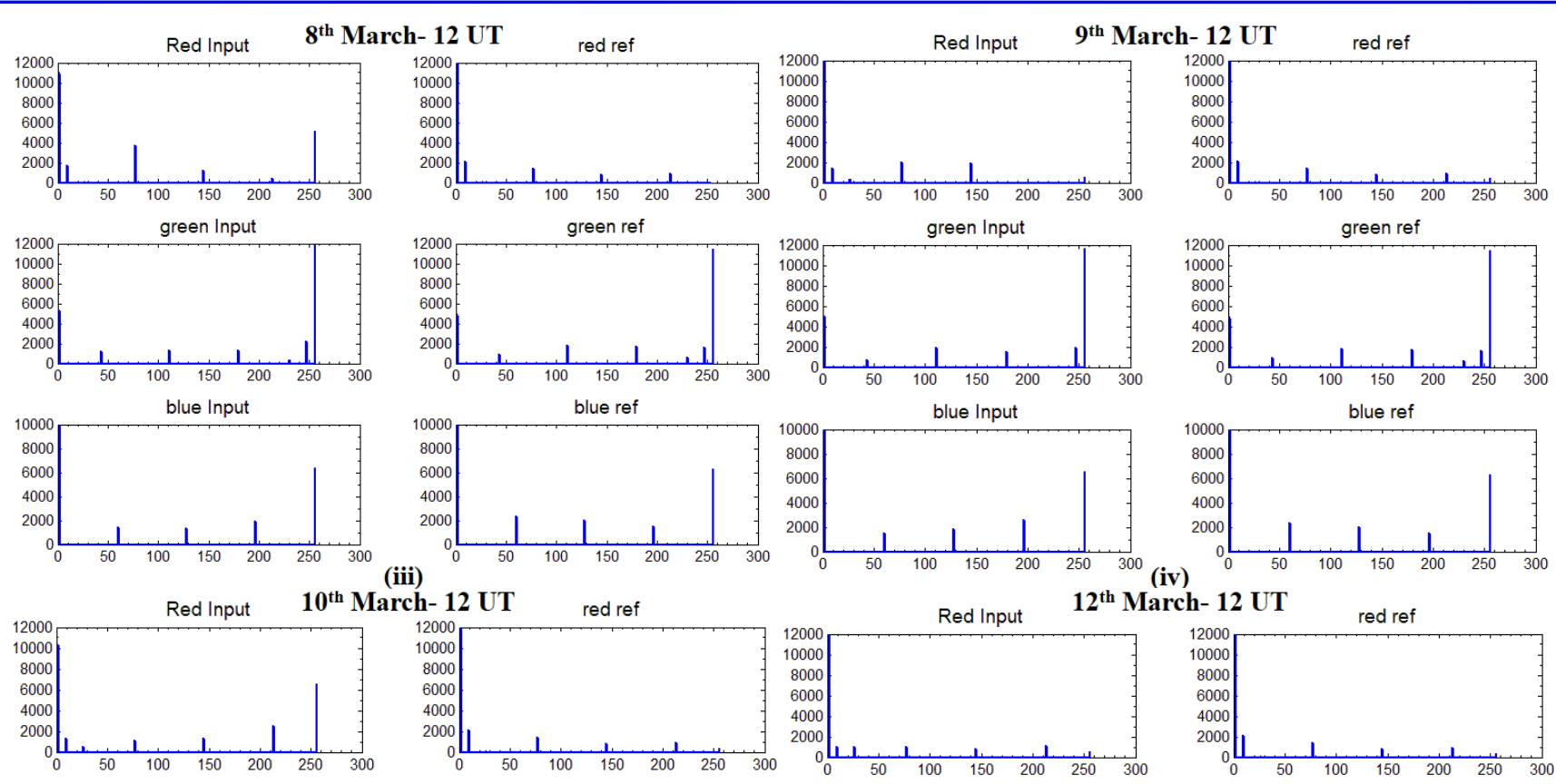

(iii)
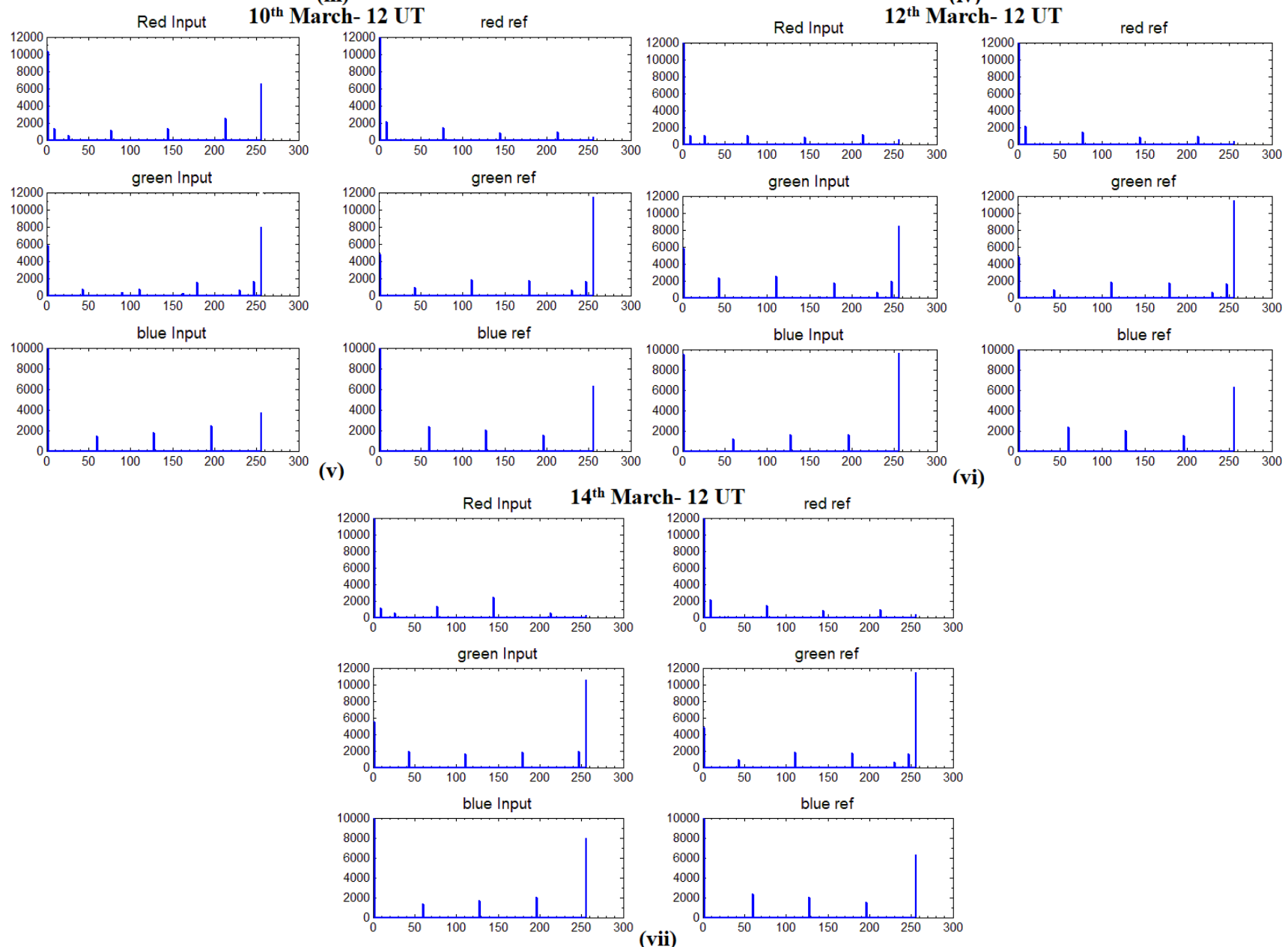

Figure 7: Shows pixel content based histogram analysis from March 6-15 covering prior to post JEQdays at 12 UT (local night hours).HerePanels (i):Low intensity of red color four days prior to EQ; (ii): Increase of red color intensity two day before EQ indicating development of EEA; (iii),(iv):Decrease of red color intensity; (v): Red color intensity value again increases on $10^{\text {th }}$ March just one day before massive JEQ of 11 March; (vi),(vii) then red color intensity decays to normal condition. 
The coded messagedisplayed in Figure 7 clearly indicates a NEA condition three days prior to March 9 EQ but development of EEA with presence of code 6 isclearly seen on $7^{\text {th }}$ March. With 5000 pixel intensity on March 8, code message 6 start decaying and totally disappear on next day.Our earlier definition of prelude to an EQ thus suggest the possible occurrence of an EQ on $8^{\text {th }}$ of March. Significantly the message 6with full intensity appeared again on March 10 and start decreasing from March 11 (not shown) and completely disappeared on March 12.Thus as per our earlier definition of prelude to an EQ the observation suggest the possible occurrence of an EQ on $8^{\text {th }}$ and the other at $11^{\text {th }}$ March,2011. The normal condition reappeared from March 14 onwards with code 3.The prediction through image processing technique seems to be reliable with actual EQ occurrence dates with a delay of maximum one day. Therefore, EEA is a good feature for extraction of EQ information from TEC profiles.

\section{Discussion and conclusions:}

The pixel analysis of global TEC contour indicatesgrowth of EEAthree to four days prior to an impending EQ around the longitude of epicentre followed by its decay and return to the normal condition after the event.Such development of EEA prior to an EQ is alsoreported by many workers [Depueva and Ruzhin 1995; Depueva and Rotanova 2001;Devi et al., 2001, 2004, 2008, 2010,2013,2018; Shvets 2002; Sorokin et al.,2011;Hayakawa 2004;Depueva et al., 2007;Park1971;Balan and Bailey1995] through TEC profile shape, enhancement /decay of equatorial anomaly observed from ground based and satellite remote sensing technique.Thus, image processing approach adopted in this paper in identifying an impending EQ at the longitude sector of the epicentre seems to be an effective tool though one cannot locate the latitudinal coordinate of the epicentre though this technique.Such latitudinal position of the epicentre have been identified by monitoring relevant other parameter like azimuthal status of different satellites coming into field of view of trans receiving line [Devi et al., 2011;Devi and Barbara 2012]. But to adopt image processing approaches in extraction of information from azimuthal position of the satellite needs special tool for conversion of the same to coded segmentation. This is the future projection of the work. But the limitation is that one needs to have ground based GPS observation near to the epicentre location at different viewing angles, achallenging task at present. The most suitable candidate for such study is nano satellites observation with multivariable sensors (probe to measure density, electric field or temperature) in the same longitudinal zone covering equator to low, mid latitude station. 


\section{References}

Anderson, D., Anghel, A., Chau, J. L.,Yumoto, K.Global Low-Latitude, Vertical E×B Drift Velocities Inferred from Daytime Magnetometer Observations. Space Weather, Vol. 4, No. 8, doi:10.1029/2005SW000193,2006.

Andreeva, E. S., Franke, S. J., Yeh, K. C., Kunitsyn, V. E. Some features of the equatorial anomaly revealed by ionospherictomography.Geophysical Research Letters, Vol. 27, No. 16, 2465-2468, august $15,2000$.

Balan, N. and Bailey, G. J.Equatorial Plasma Fountain and Its Effects: Possibility of an Additional Layer.Journal of Geophysical Research, Vol. 100, No. A11, 21421- 21432,1995.

Chitradevi, B., Srimathi, P. An Overview on Image Processing Techniques.International Journal of Innovative Research in Computer and Communication Engineering, Vol. 2, No. 11, www.ijircce.com, November 2014.

Depueva, A. H. and Ruzhin, Yu. Ya.Seismoionospheric Fountain Effect as Analogue of Active Space Experiment.Advances in Space Research, Vol. 15, No. 12, 12-15,doi:10.1016/0273-1177(95)00036E,1995.

Depueva, A. H. and Rotanova, N. M. Low-Latitude Ionospheric Disturbances Associated with Earthquakes.Annals of Geophysics, Vol. 44, No. 2,221-228, 2001.

Devi, M., Barman, M.K., Barbara, A.K.,Depueva, A.H. Total electron content near anomaly crest as precursor of earthquake.Indian Journal of Radio \& Space Phyics, 30,209-213,2001.

Devi, M., Barbara, A.K.,Depueva, A.H. Association of total electron content and foF2 variations with earthquake events at the anomaly crest region.Annals of Geophysics, 47, 83-91,2004.

Devi, M., Barbara, A. K., Depueva, A. H., Depueva,V.Preliminary Results of TEC Measurements in Guwahati, India.Advances in Space Research, Vol. 42, No. 4, 753756, doi:10.1016/j.asr.2008.01.020,2008.

Devi, M., Barbara,A. K., Kashyap, P., Depueva,A. H., Ruzhin,Yu. Ya.DepuevaV.Earthquake Time Low Latitude TEC and Model Estimated Values: Identification on Earthquake Induced Atmospheric Dynamics.Advances of Geosciences, Vol. 26, 69-84,2010.

Devi, M., Sarma, A.J.D., Kalita, S., Barbara, A. K.,Depueva,A.Adaptive techniques for extraction of pre-seismic parameters of total electron content (TEC) at anomaly crest station.Geomatics, Natural Hazards and Risk, DOI: 10.1080/19475705.2011.595831,2011. 
Devi, M. and Barbara,A.K.Total Electron Content and Anomalous Appearance of GPS Satellites as Pointers to Epicentre Identification of Major Japan Earthquake of 2011.Positioning, Vol. 3, No. 1, 7 12, http://www.SciRP.org/journal/pos,2012.

Devi, M., Medhi, A., Sarma, A.J., Barbara, A.K. Growth and Inhibition of Equatorial Anomaly Prior to an Earthquake (EQ): Case Studies with Total Electron Content (TEC) Data for Major EQs of Japan 2011 and Indonesia 2012.Positioning, 4, 240-252,http://dx.doi.org/10.4236/pos.2013.43024,2013.

Devi, M., Patgiri, S., Barbara, A.K., Oyama, K.I., Ryu, K., Depuev, V., Depueva, A. Role of Equatorial Anomaly in Earthquake time precursive features: A few strong events over West Pacific zone. Advances in space research,Vol 61, No-6,1444-1455,https://doi.org/10.1016/j.asr.2018.01.003, 2018.

Gonzalez, Rafael C. and Woods, Richard E. Digital Image Processing, 3rd ed., Prentice Hall: USA. ISBN-10: 013168728X | ISBN-13: 978-0131687288,2007.

Gonzalez Rafael C., Woods Richard E., Eddins Steven L.Digital Image Processing Using MATLAB® Second Edition.ISBN 978-0-9820854-0-0,2009.

Horvath I and Essex E. A. Vertical E $\times$ B Drift Velocity Variations and Associated Low-Latitude Ionospheric Irregularities Investigated with the TOPEX and GPS Satellite Data.Annals of Geophysics, European Geosciences Union, Vol. 21, 1017-1030. doi:10.5194/angeo-21-1017-2003,2003.

Jain A.K.Fundamentalsof Digital Image Processing. Prentice-Hall, 1989.

Jenson John R.Digital Image Processing - A Remote Sensing Perspective, $3{ }^{\text {rd }}$ Edition. Prentice - Hall, 2003.

Khotanzad A. and Hong Y.H.Invariant image recognition by Zernike moments.IEEE Trans. Pattern Analysis and Machine Intelligence, 12, 489-497, 1990.

Park C. G.Westward Electric Fields as the Cause of Nighttime Enhancements in Electron Concentrations in Mid Latitude F-Region.Journal of Geophysical Research, Vol. 76, No. 19,45604568. doi:10.1029/JA076i019p04560,1971.

Ryszard S. Choras. Image Feature Extraction Techniques and Their Applications for CBIR and Biometrics Systems.International Journal of Biology and Biomedical Engineering; Vol 1,No-1, 2007.

Saber E., Tekalp A.M. Integration of color, edge and texture features for automatic region-based image annotation and retrieval.Electronic Imaging, 7, 684-700, 1998.

Shih, Frank Y. Image Processing and Pattern Recognition: Fundamentals and Techniques.Wiley-IEE, 2010. 
Shvets A. V., Hayakawa M., Molchanov O. A.Sub-ionospheric VLF Monitoring for Earthquake Related IonosphericPerturbations.Journal of Atmospheric Electricity, Vol. 22,87-99,2002.

Sorokin V. M., Ruzhin Y. Y., Yaschenko A. K., Hayakawa M.Generation of VHF Radio Emissions by Electric Discharges in the Lower Atmosphere over a Seismic Region.Journal of Atmospheric and Solar-Terrestrial Physics, Vol. 73, No. 5-6, 664-670. doi:10.1016/j.jastp.2011.01.016,2011.

Walker G. O. and Chen H. F.Computer Simulation of the Seasonal Variations of Ionospheric Equatorial Anomaly in East Asia under Solar Minimum Conditions.Journal of Atmospheric and Terrestrial Physics, Vol. 51, No. 11-12, 953-974. doi:10.1016/0021-9169(89)90011-1,1989.

Zaslavski, Y., Parrot, M., Blanc, E.Analysis of TEC measurements above 180, active seismic regions.Physics of the Earth and Planetary Interiors, 105, 219-228, 1998. 